\title{
Recommendations for avoiding knee pain after intramedullary nailing of tibial shaft fractures
}

\author{
Pedro José Labronici ${ }^{1}$, Robinson Esteves Santos Pires ${ }^{2 *}$, José Sérgio Franco ${ }^{3}$, Hélio Jorge Alvachian Fernandes ${ }^{4}$ and \\ Fernando Baldy dos Reis ${ }^{4}$
}

\begin{abstract}
Background: The objective of this study is to analyze the proximal tibiofibular joint in patients with knee pain after treatment of tibial shaft fractures with locked intramedullary nail.

Findings: The proximal tibiofibular joint was analyzed in 30 patients, who reported knee pain after tibial nailing, and standard radiograph and computed tomography were performed to examine the proximal third of the tibia. Twenty patients (68.9\%) presented the proximal screw crossing the proximal tibiofibular joint and 13 (44.8\%) had already removed the nail and/or screw. Four patients (13.7\%) reported complaint of knee pain. However, the screw did not reach the proximal tibiofibular joint. Five patients (17.2\%) complained of knee pain although the screw toward the joint did not affect the proximal tibiofibular joint.

Conclusion: When using nails with oblique proximal lock, surgeons should be careful not to cause injury in the proximal tibiofibular joint, what may be one of the causes of knee pain. Thus, the authors suggest postoperative evaluation performing computed tomography when there is complaint of pain.
\end{abstract}

\section{Background}

Tibial shaft fracture is considered the most common long bone in orthopaedic practice. Fixation with intramedullary nail has frequently been used and proven to be efficient in displaced tibial shaft fractures [1-8]. Tibial nailing is related with relatively low incidence of nonunion, malunion, infection and compartmental syndrome [9-11]. However, pain in the knee joint is the most common complication after tibial nailing. Its occurrence has been reported from 10 to $86 \%$ of the cases, particularly in young and active patients [12-16]. A recent meta-analysis of the literature has estimated an incidence of 47.4\% [11]. Although the etiology of the knee pain after intramedullary nail is still unknown, many theories have been proposed [11,13,17-19].

Several anatomic structures around the knee are prone to damage during nail insertion, including the patellar tendon $[11,14]$, menisci, articular cartilage, the infrapatellar branch of the saphenous nerve and infrapatellar fat pad [14]. Additionally, the presence of prominent nail and/or screw and the associated muscular weakness have

\footnotetext{
* Correspondence: robinsonesteves@ig.com.br

${ }^{2}$ Department of Orthopaedic Surgery, Federal University of Minas Gerais and Felício Rocho Hospital, Belo Horizonte, MG, Brazil

Full list of author information is available at the end of the article
}

been described as causative factors of pain [20]. Some nail designs, with the oblique screw in the proximal aspect, have proven to be biomechanically more stable in tibial fractures. Nevertheless, with this type of fixation, the proximal screw may injure the proximal tibiofibular joint, what may cause knee pain [21].

Our purpose was to analyze the proximal tibiofibular joint, performing computed tomography in 30 patients with knee pain after locked intramedullary nailing in tibial shaft fractures.

\section{Methods}

We retrospectively reviewed a hundred patients with displaced tibial shaft fractures treated with locked intramedullary nailing in a general hospital, between 2000 and 2004. Thirty patients reported knee pain after the procedure and were analyzed through standard radiograph and computed tomography of the proximal third of the tibia (axial cuts). All surgeries were performed by the same surgeon utilizing the same nail design. A patient lost the computed tomography and was excluded. All patients had been treated with unreamed locked intramedullary nail with proximal oblique screws. The age ranged from 18 to
C Biomed Central

(c) 2011 Labronici et al; licensee BioMed Central Ltd. This is an Open Access article distributed under the terms of the Creative Commons Attribution License (http://creativecommons.org/licenses/by/2.0), which permits unrestricted use, distribution, and reproduction in any medium, provided the original work is properly cited. 
71 years old. The mean age was 36 years old. Twenty-two were male and seven were female.

The distance between the nail with the tibial plateau and the anterior cortex of the tibia was analyzed in the lateral view radiographs according to the method of Keating et al [13]. All radiographs were taken with standard distance of $90 \mathrm{~cm}$. The height of the nail was defined in the lateral view radiograph as the distance between the line drawn through the tibial plateau and a parallel line to this strip that touches the apex of the nail. Negative values mean that the nail would be buried in the proximal metaphyseal aspect of the tibia. Positive values show the amount of prominence of the nail in relation to the tibial plateau. The distance of the cortex with anterior nail was defined between a line drawn above the anterior cortex of tibia and the anterior apex of the nail. Patients without nails and/or screws were included, assessing the measures from previous radiographs.

The CT scan of the proximal metaphyseal aspect of the tibia was evaluated for the proximal locking screw crossing the proximal tibiofibular joint, avoiding the joint or directed toward the joint but without penetrating the joint. (Figures 1 and 2).

Approval by the ethics committee of the institution involved in the study was obtained.

\section{Results}

Among a hundred patients treated with intramedullary nailing after tibial shaft fractures, 30\% complained of knee pain. A patient lost the computed tomography and was excluded. Performing the computed tomography, it was observed that 20 patients $(68.9 \%)$ had the proximal screw crossing the proximal tibiofibular joint and 13 (44.8\%) had already taken out nail and/or screw. Four patients (13.7\%) presented complaints of knee pain although the screw did

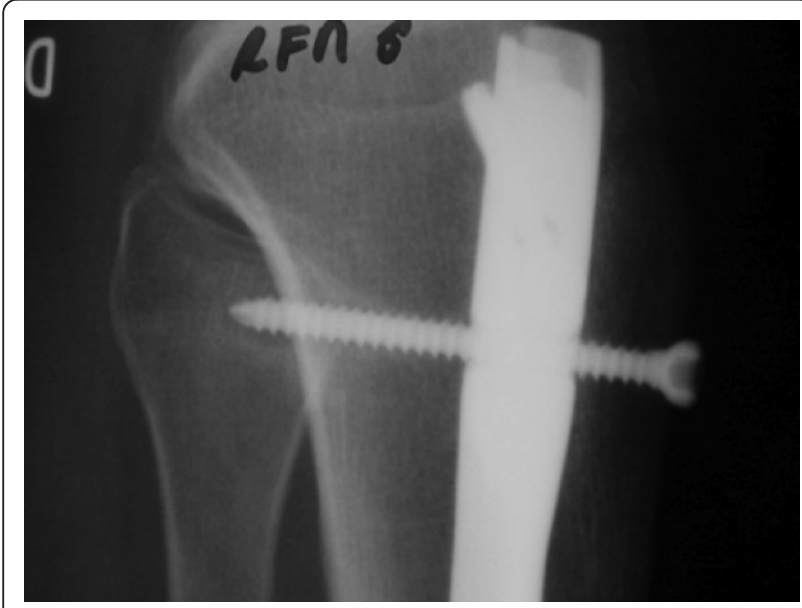

Figure $1 \mathrm{X}$-ray in lateral view with the oblique screw crossing the proximal tibiofibular joint.

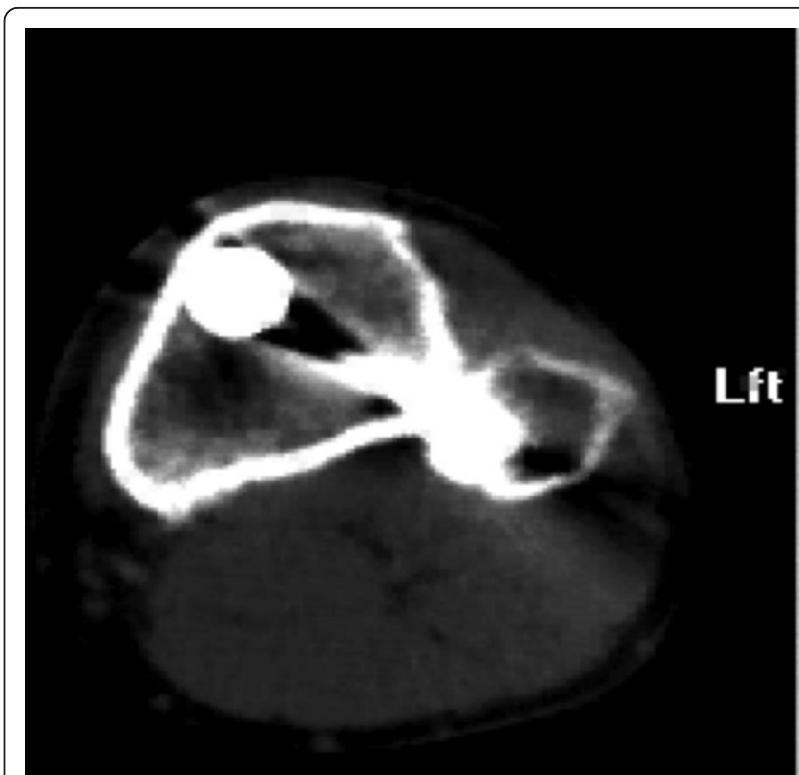

Figure 2 Computed tomography in axial cut showing the screw crossing the proximal tibiofibular joint.

not reach the proximal tibiofibular joint and there was no nail prominence in tibial plateau level as well as in the anterior cortex of tibia. In five patients (17.2\%), the screw was toward the joint, but it did not affect the proximal tibiofibular joint. In one patient, the nail was $0.5 \mathrm{~mm}$ prominent in relation to the anterior cortex of tibia and another presented the nail $0.5 \mathrm{~mm}$ prominent in relation to the anterior cortex and $0.5 \mathrm{~mm}$ in the tibial plateau level. Four patients (13.3\%) presented the nail above the tibial plateau varying from $0.3 \mathrm{~mm}$ to $0.7 \mathrm{~mm}$ with an average of $0.5 \mathrm{~mm}$. Of these, three also presented the screw in the proximal tibiofibular joint. In six patients (20.6\%), the prominent nail in relation to the anterior cortex of tibia ranged between $0.3 \mathrm{~mm}$ and $0.5 \mathrm{~mm}$ with an average of $0.4 \mathrm{~mm}$. Four of these had the screw in the proximal tibiofibular joint (Table 1).

\section{Discussion}

There are many studies describing knee pain after treatment of tibial shaft fractures with locked intramedullary nail $[11,12,16,18,21-23]$.

Although the etiology of pain is still unknown, it seems to be multifactorial. Several studies have been carried out to identify the causes of pain $[11,13,14,20]$. Meta-analysis with 20 studies evaluating knee pain after intramedullary nail has shown a mean prevalence of $47.4 \%(10 \%-86 \%)$ [11]. This study has shown prevalence of $30 \%$, which could be attributed to the fact that we used unreamed nail, with smaller diameter, which consequently caused less injury to the bone and to the soft tissues during the nail insertion. 
Table 1 Patients with complaint of knee pain after intramedullary nailing

\begin{tabular}{|c|c|c|c|c|c|c|c|}
\hline Age & Gender & $\begin{array}{l}\text { Screw in the } \\
\text { joint }\end{array}$ & $\begin{array}{c}\text { Screw out of the } \\
\text { joint }\end{array}$ & $\begin{array}{c}\text { Without nail and/or } \\
\text { screw }\end{array}$ & $\begin{array}{c}\text { Screw toward the } \\
\text { joint }\end{array}$ & $\begin{array}{l}\text { Nail above the } \\
\text { plateau }\end{array}$ & $\begin{array}{l}\text { Prominent nail anterior } \\
\text { cortex }\end{array}$ \\
\hline 57 & FEMALE & $x$ & & & & $\mathrm{NO}$ & $\mathrm{NO}$ \\
\hline 57 & MALE & & & & $x$ & $0,5 \mathrm{~mm}$ & $0,5 \mathrm{~mm}$ \\
\hline 25 & MALE & $x$ & & $x$ & & NO & NO \\
\hline 33 & MALE & $x$ & & $x$ & & $\mathrm{NO}$ & $\mathrm{NO}$ \\
\hline 29 & FEMALE & $x$ & & $x$ & & NO & NO \\
\hline 43 & FEMALE & $x$ & & $x$ & & NO & NO \\
\hline 26 & FEMALE & $x$ & & $x$ & & NO & NO \\
\hline 31 & MALE & $x$ & & & & NO & $0,3 \mathrm{~mm}$ \\
\hline 18 & MALE & $x$ & & $x$ & & $\mathrm{NO}$ & NO \\
\hline 19 & MALE & $x$ & & & & NO & NO \\
\hline 30 & MALE & $x$ & & & & NO & NO \\
\hline 41 & MALE & & $x$ & & & NO & NO \\
\hline 52 & MALE & & & & $x$ & NO & $0,5 \mathrm{~mm}$ \\
\hline 56 & FEMALE & & $x$ & & & NO & NO \\
\hline 71 & FEMALE & & $x$ & & & NO & NO \\
\hline 27 & MALE & $x$ & & & & NO & $\mathrm{NO}$ \\
\hline 38 & MALE & $x$ & & $x$ & & NO & $0,4 \mathrm{~mm}$ \\
\hline 54 & MALE & & & $x$ & $x$ & NO & NO \\
\hline 29 & MALE & $x$ & & & & NO & $\mathrm{NO}$ \\
\hline 59 & MALE & $x$ & & $x$ & & $0,3 \mathrm{~mm}$ & $0,3 \mathrm{~mm}$ \\
\hline 36 & MALE & $x$ & & & & $0,6 \mathrm{~mm}$ & $0,3 \mathrm{~mm}$ \\
\hline 31 & MALE & & & & $x$ & NO & NO \\
\hline 36 & FEMALE & $x$ & & & & NO & NO \\
\hline 21 & MALE & $x$ & & & & $0,7 \mathrm{~mm}$ & NO \\
\hline 21 & MALE & $x$ & & $x$ & & NO & NO \\
\hline 18 & MALE & & & $x$ & $x$ & NO & $\mathrm{NO}$ \\
\hline 26 & MALE & $x$ & & $x$ & & NO & NO \\
\hline 27 & MALE & $x$ & & $x$ & & NO & NO \\
\hline 34 & MALE & & $x$ & & & NO & $\mathrm{NO}$ \\
\hline
\end{tabular}

The choice of surgical approach, particularly through the transpatellar or parapatellar tendon, has been reported as a contributory factor of knee pain after nail insertion. Several authors suggest that the transpatellar approach is more likely to present higher risks. Furthermore, it is more commonly associated with knee pain in the post-operatory due to its incision through the tendon, to the retro-tendinous fat pad-injury, which is highly innervated $[13,17,24,25]$. When parapatellar approach is used, the patellar tendon, the retropatellar fat pad and the tissues are retracted and, theoretically there would be no tissue injury. The trauma caused by the retractors during reaming could cause knee pain $[11,13,14,19,26]$. In this study, we used the medial parapatellar approach for nail insertion in all patients. It was our belief that with this approach we would be able to protect the tendon from one more trauma decreasing the likelihood of causing knee pain.

The distance of the nail, from the proximal entry point in the tibial plateau or in the anterior tibial cortex, does not have relation with knee pain [27]. Keating et al [13] reported that the mean distance between the nail and the plateau was $13 \mathrm{~mm}$ and concluded that knee pain happened independent of this distance. Additionally, knee pain was observed in $57 \%$ of the patients with $5 \mathrm{~mm}$ of the nail in the exterior aspect of the anterior cortex of tibia. Utilizing the distance nail-plateau and nail-anterior cortex as parameters of assessment, Bhattacharyya et al [15] demonstrated that, when the nail was buried $1.25 \mathrm{~cm}$ in relation to the tibial plateau, in the coronal and sagittal axes, the pain decreased significantly. However, the authors did not establish a limit [15]. Uzumcugiletal et al [27] verified that in the knee pain group, although the mean distance in the tibia plateau was $11.5 \pm 7.9 \mathrm{~mm}$, the pain persisted. In a metaanalysis published in 2006, which examined knee pain after intramedullary nailing procedure, it was suggested that the prominent nail should be avoided. However, no absolute values of de distance were shown [11]. Our study observed that $13.3 \%$ of the patients with knee pain 
had the nail above the tibial plateau. In three, pain was related to the screw in the proximal tibiofibular joint. In six patients, $(20.6 \%)$ the nail was prominent to the anterior tibial cortex. Of these, in four the pain was associated with the screw in the proximal tibiofibular joint. Nevertheless, it is important to point out that the patients who did not report knee pain, although they had prominent nail in the tibial plateau and in the anterior cortex aspect, were not assessed. Neither was analyzed the depth of the nail in relation to the proximal interlock. It is also important to highlight that, when using some nails with oblique lock, it is necessary to cross the lateral cortex to obtain fracture stability.

Laidlaw et al [21] were the first to document the injury in the proximal tibiofibular joint after insertion of the medial interlock screw with oblique lock nails in tibial shaft fractures. They used the interface of a clock to a correlated to a lock in the position of 2 o'clock, as intraoperatory evaluation of the proximal tibiofibular joint. Thus, they avoided the "danger zone", which was found to be between $44.7^{\circ}$ to $72.1^{\circ}$ on the right from $40.6^{\circ}$ to $73.0^{\circ}$ on the left. They also pointed out that the surgeons should be aware of this complication and avoid either the placement of the screw in the posterolateral direction or the interlock screw crossing the lateral cortex. In our study, 30 patients complained of knee pain when treated with proximal oblique interlock nails. Of these, 20 presented injury in the joint, confirmed through computed tomography. We believe that, when using this nail design, the surgeon should be careful with the direction of the interlock screw to avoid injury in the tibiofibular joint. Thus, preventing one more causative factor after placement of intramedullary nail in tibial shaft fractures.

As strengths, this study demonstrates that the direction of the proximal screw from anteromedial to posterolateral, depending on the height of the nail can reach the proximal tibiofibular joint and be a potential cause of knee pain. Current literature is scarce on the subject and we believe that this information will serve as a warning to orthopaedic surgeons about this potential complication. In addition, the first study that cited such complications had a sample size of 2 patients [21]. This study presents 20 patients with violation of the proximal tibiofibular joint with oblique locking screws. As weaknesses of this paper, we address specifically a potential cause of knee pain after osteosynthesis of tibial shaft fractures with locked intramedullary nails. We can't attribute the pain exclusively to this cause, since knee pain after tibial nailing is multifactorial.

As a final comment, it should be noted, as Bhattacharyya et al [15] asserts that surgical damage, not the injury, plays a fundamental role in the etiology of knee pain after nailing. Knee pain after intramedullary nailing is most likely related to the operative procedure in the nail insertion rather than the traumatic event which caused the injury.

\section{Conclusion}

Knee pain is a common complication of tibial shaft fractures treated with intramedullary nailing. A significant cause of knee pain appears to be violation of the proximal tibiofibular join by oblique locking screws. The surgeon should be careful not to penetrate tibiofibular joint when utilizing this nail design.

\section{Consent Statement}

Written informed consent to publish the case reports and the accompanying images was obtained from all of the patients concerned.

\section{Author details}

'Department of Orthopaedic Surgery, Santa Tereza Hospital, Petrópolis, RJ, Brazil. ${ }^{2}$ Department of Orthopaedic Surgery, Federal University of Minas Gerais and Felício Rocho Hospital, Belo Horizonte, MG, Brazil. ${ }^{3}$ Department of Orthopaedic Surgery, Federal University of Rio de Janeiro, Rio de Janeiro, RJ, Brazil. ${ }^{4}$ Department of Orthopaedic Surgery, Federal University of São Paulo, São Paulo, SP, Brazil.

\section{Authors' contributions}

$P J L$ and JSF were responsible for developing the idea of this study. PJL, JSF, RESP, HJAF and FBR contributed to the study design. PJL was involved in reviewing records and in data acquisition. PJL, JSF, HJAF, RESP, FBR performed the literature review and drafting of the manuscript. PJL performed all surgeries.

All authors were involved in reviewing and editing the manuscript and all have approved the final manuscript.

\section{Competing interests}

The authors declare that they have no competing interests.

Received: 27 August 2011 Accepted: 1 December 2011 Published: 1 December 2011

\section{References}

1. Fanian $H$, Dehghani $M$ : Anterior knee pain after unreamed intramedullary nailing of the tibia. JRMS 2008, 13(5):260-3.

2. Alho A, Benterud JG, Hogevold HE: Comparison of functional bracing and locked intramedullary nailing in the treatment of displaced tibial shaft fractures. Clin Orthop Relat Res 1992, 277:243-50.

3. Blachut PA, O'Brien PJ, Meek RN, Broekhuyse HM: Interlocking intramedullary nailing with and without reaming for the treatment of closed fractures of the tibial shaft. A prospective, randomized study. J Bone Joint Surg Am 1997, 79(5):640-6.

4. Bone LB, Sucato D, Stegemann PM, Rohrbacher BJ: Displaced isolated fractures of the tibial shaft treated with either a cast or intramedullary nailing. An outcome analysis of matched pairs of patients. J Bone Joint Surg Am 1997, 79(9):1336-41.

5. Bone $L B$, Johnson KD: Treatment of tibial fractures by reaming and intramedullary nailing. J Bone Joint Surg Am 1986, 68(6):877-87.

6. Court-Brown CM, Will E, Christie J, McQueen M: Reamed or unreamed nailing for closed tibial shaft fractures. J Bone Joint Surg Br 1996, 78(4):580-3.

7. Finkemeier C, Schmidt AH, Kyle RF, Templeman DC, Varecka TF: A prospective, randomized study of intramedullary nails inserted with and without reaming for the treatment of open and closed fractures of the tibial shaft. J Orthop Trauma 2000, 14(3):187-93.

8. Bhandari M, Guyatt $G$, Tornetta $P$, Schemitsch EH: Study to prospectively evaluate reamed intramedullary nails in patients with tibial fractures 
(SPRINT): study rationale and design. BMC Musculoskelet Disord 2008, 23:1-15.

9. Sanders R, Jersinovich I, Anglen J, DiPasquale T, Herscovici D Jr: The treatment of open tibial shaft fractures using an interlocked intramedullary nail without reaming. J Orthop Trauma 1994, 8(6):504-10.

10. Hass N, Krettek C, Schandelmaier P, Frigg R, Tscherne H: A new solid unreamed tibial nail for shaft fractures with severe soft tissue injury. Injury 1993, 24:49-54.

11. Katsoulis E, Court-Brown C, Giannoudis PV: Incidence and etiology of anterior knee pain after intramedullary nailing of the femur and tibia. J Bone Joint Surg 2006, 88B(5):576-80.

12. Court-Brown CM, Gustilo T, Shaw AD: Knee pain after intramedullary tibial nailing: its incidence, etiology, and outcome. J Orthop Trauma 1997, 11(2):103-5.

13. Keating JF, Orfaly R, O'Brien PJ: Knee pain after tibial nailing. Journal of Orthop Trauma 1997, 11(1):10-3.

14. Toivanen JA, Vaisto O, Kannus P, Latvala K, Honkonen SE, Jarvinen MJ: Anterior knee pain after intramedullary nailing of fractures of the tibial shaft: a prospective, randomized study comparing two different nailinsertion techniques. J Bone Joint Surg 2002, 84A(4):580-85.

15. Bhattacharyya T, Seng K, Nassif NA, Freedman I: Knee pain after tibial nailing. The role of nail prominence. Clin Orthop Relat Res 2006, 449:303-7.

16. Karachalios T, Babis G, Tsarouchas J, Sapkas G, Pantazopoulos T: The clinical performance of a small diameter tibial nailing system with a mechanical distal aiming device. Injury 2000, 31:451-59.

17. Orfaly $R$, Keating JE, O'Brien PJ: Knee pain after tibial nailing: does the entry point matter? J Bone Joint Surg 1995, 77B(6):976-77.

18. Hernigou P, Cohen D: Proximal entry for intramedullary nailing of the tibia: the risk of unrecognized articular damage. J Bone Joint Surg 2000, 82B(1):33-41.

19. Vaisto O, Toivanen J, Paakkala T, Jarvela T, Kannus P, Jarvinen M: Anterior knee pain after intramedullary nailing of the tibial shaft fracture: an ultrasound study of the patellar tendons of 36 patients. J Orthop Trauma 2005, 19(5):311-16

20. Vaisto $O$, Toivanen J, Kannus $P$, Järvinen $M$ : Anterior knee pain and thigh muscle strength after intramedullary nailing of tibial shaft fractures: a report of 40 consecutive cases. J Orthop Trauma 2004, 18(1):18-23.

21. Laidlaw MS, Ehmer N, Matityahu A: Proximal tibiofibular joint pain after insertion of a tibial intramedullary nail: Two case reports with accompanying computed tomography and cadaveric studies. J Orthop Trauma 2010, 24(6):e58-e64.

22. Vaisto $\mathrm{O}$, Toivanen J, Kannus $\mathrm{P}$, Järvinen $\mathrm{M}$ : Anterior knee pain after intramedullary nailing of fractures of the tibial shaft: an eight-year follow-up of a prospective, randomized study comparing two different nail-insertion techiniques. J Trauma 2008, 64(6):1511-6.

23. Cartwright-Terry M, Snow M, Nalwad H: The severity and prediction of anterior knee pain post tibial nail insertion. J Orthop Trauma 2007, 21(6):381-85.

24. Koval KJ, Clapper MF, Brumback RJ, Ellison PS Jr, Poka A, Bathon GH, Burgess AR: Complications of reamed intramedullary nailing of the tibia. J Orthop Trauma 1991, 5(2):184-89.

25. Yu SW, Tu YK, Fan KF, Su JY: Anterior knee pain after intramedullary tibial nailing. Changgeng Yi XueZaZhi 1999, 22:604-8.

26. Althausen PL, Neiman R, Finkmeier CG, Olson SA: Incision placement for intramedullary tibial nailing: an anatomic study. J Orthop Trauma 2002, 16(10):687-90.

27. Uzumcugil O, Dogan A, Yalcinkaya M, Kabukcuoglu YS: The relationship between anterior knee pain occurring after tibial intramedullary nailing and the localization of the nail in the proximal tibia. Acta Orthop Traumatol Turc 2009, 43(5):386-89.

doi:10.1186/1754-9493-5-31

Cite this article as: Labronici et al: Recommendations for avoiding knee pain after intramedullary nailing of tibial shaft fractures. Patient Safety in Surgery 2011 5:31.

\section{Submit your next manuscript to BioMed Central and take full advantage of:}

- Convenient online submission

- Thorough peer review

- No space constraints or color figure charges

- Immediate publication on acceptance

- Inclusion in PubMed, CAS, Scopus and Google Scholar

- Research which is freely available for redistribution

Submit your manuscript at www.biomedcentral.com/submit
Biomed Central 